\title{
Impact of intercropping on the coupling between soil microbial community structure, activity, and nutrient-use efficiencies
}

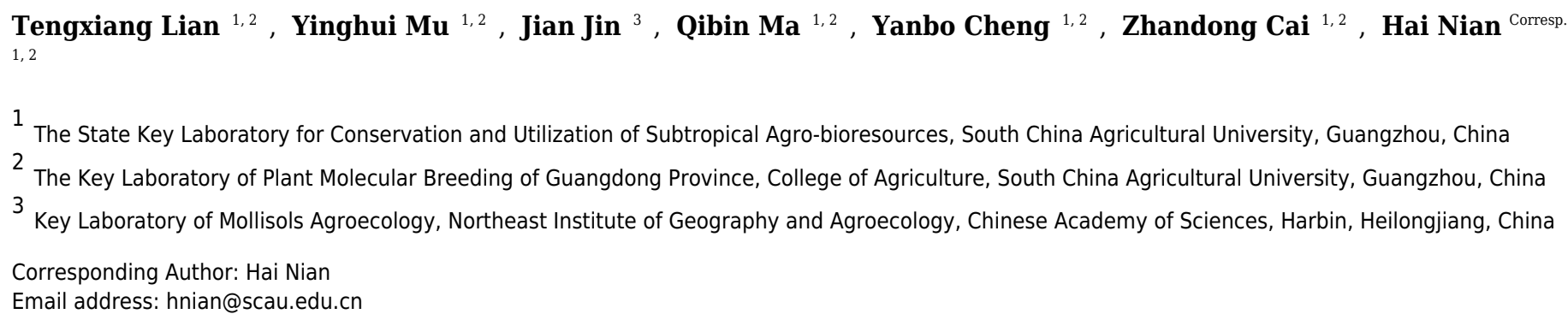

Sugarcane-soybean intercropping has been widely used to control disease and improve nutrition in the field. However, the response of the soil microbial community diversity and structure to intercropping is not well understood. Since microbial diversity corresponds to soil quality and plant health, a pot experiment was conducted with sugarcane intercropped with soybean. Rhizosphere soil was collected 40 days after sowing, and MiSeq sequencing was utilized to analyse the soil microbial community diversity and composition. Soil columns were used to assess the influence of intercropping on soil microbial activity ( soil respiration and carbon-use efficiency : nitrogen-use efficiency ratio ). PICRUSt and FUNGuild analysis were conducted to predict microbial functional profiling. Our results showed that intercropping decreased $\mathrm{pH}$ by approximately $8.9 \%$ and enhanced the soil organic carbon $(\mathrm{SOC})$, dissolved organic carbon (DOC), and available nitrogen (N) by $5.5 \%$, $13.4 \%$ and $10.0 \%$, respectively. These changes in physicochemical properties corresponded to increased microbial diversity and shifts in soil microbial communities. Microbial community correlated significantly $(p<0.05)$ with soil respiration rates and nutrient use efficiency . Furthermore, intercropping influenced microbial functions, such as carbon fixation pathways in prokaryotes, citrate cycle (TCA cycle) of bacteria and wood saprotrophs of fungi. These overrepresented functions might accelerate nutrient conversion and control phytopathogens in soil. 
2 Title: Impact of intercropping on the coupling between soil microbial community structure,

3 activity, and nutrient-use efficiencies

4 Tengxiang Lian ${ }^{1,2}$, Yinghui $\mathrm{Mu}^{1,2}$, Jian $\mathrm{Jin}^{3}$, Qibin $\mathrm{Ma}^{1,2}$, Yanbo Cheng ${ }^{1,2}$, Zhandong Cai ${ }^{1,2}$, Hai

$5 \operatorname{Nian}^{1,2 *}$

6 1.The State Key Laboratory for Conservation and Utilization of Subtropical Agro-bioresources,

7 South China Agricultural University, Guangzhou 510642, Guangdong, People’s Republic of

8 China

9 2.The Key Laboratory of Plant Molecular Breeding of Guangdong Province, College of

10 Agriculture, South China Agricultural University, Guangzhou 510642, Guangdong, People’s

11 Republic of China

12 3.Key Laboratory of Mollisols Agroecology, Northeast Institute of Geography and Agroecology,

13 Chinese Academy of Sciences, Harbin 150081, China

* Corresponding author: Hai Nian

16 Corresponding address: No.483 Wushan Road, Guangzhou, Guangdong, 510642, China.

17 Tel.: +8602085288024

Fax: +8602085288024 
19 E-mail address: hnian@scau.edu.cn

\section{Abstract}

21 Sugarcane-soybean intercropping has been widely used to control disease and improve nutrition

22 in the field. However, the response of the soil microbial community diversity and structure to

23 intercropping is not well understood. Since microbial diversity corresponds to soil quality and

24 plant health, a pot experiment was conducted with sugarcane intercropped with soybean.

25 Rhizosphere soil was collected 40 days after sowing, and MiSeq sequencing was utilized to

26 analyse the soil microbial community diversity and composition. Soil columns were used to

27 assess the influence of intercropping on soil microbial activity (soil respiration and carbon-use

28 efficiency : nitrogen-use efficiency ratio). PICRUSt and FUNGuild analysis were conducted to

29 predict microbial functional profiling. Our results showed that intercropping decreased $\mathrm{pH}$ by

30 approximately $8.9 \%$ and enhanced the soil organic carbon (SOC), dissolved organic carbon

31 (DOC), and available nitrogen $(\mathrm{N})$ by $5.5 \%, 13.4 \%$ and $10.0 \%$, respectively. These changes in

32 physicochemical properties corresponded to increased microbial diversity and shifts in soil

33 microbial communities. Microbial community correlated significantly $(p<0.05)$ with soil

34 respiration rates and nutrient use efficiency. Furthermore, intercropping influenced microbial

35 functions, such as carbon fixation pathways in prokaryotes, citrate cycle (TCA cycle) of bacteria

36 and wood saprotrophs of fungi. These overrepresented functions might accelerate nutrient

37 conversion and control phytopathogens in soil. 


\section{Introduction}

42 Sugarcane-soybean intercropping has been widely used to stabilize yields and reduce nitrogen

43 leaching (Edwin et al., 2005; Xu et al., 2008; Li et al., 2013). N fixation associated with

44 soybeans can improve soil fertility and field ecological conditions that favor sugarcane in the

45 intercropping system (He et al., 2006). Intercropping of sugarcane with soybean, may also

46 stimulate $\mathrm{N}$ fixation by the legume's microbiome (Li et al., 2013).

47 In an intercropping system, the roots of different plant species interact directly with each other and subsequently affect root exudation, which undoubtedly alters the microbial diversity, structure, and activity (Zhou et al., 2011; Broeckling et al., 2008; Gomes et al., 2003). The changed microbial community and activity by intercropping could affect $\mathrm{C}$ and $\mathrm{N}$ dynamics

51 (Kaur et al., 2000; Rowe et al., 2005; Sun et al., 2009), and this may be attributed to the ability of microbial communities to regulate carbon and nitrogen-use efficiency (Mooshammer et al., 2014). Thus, a comprehensive method that incorporates the carbon-use efficiency : nitrogen-use efficiency ratio and soil respiration could be used to evaluate the change in microbial activity caused by the microbial community (Zhong et al., 2015). several intercropping systems, including mulberry-soybean, Eucalyptus-Acacia mangium and 
58 apple tree-crown vetch intercropping (Li et al., 2013; Li et al., 2016; Rachid et al., 2015, Zheng

59 et al., 2018). For example, Li et al. (2016) investigated the effects of mulberry-soybean

60 intercropping on the diversity and composition of the soil bacterial community in salt-alkali soil

61 and found that intercropping increased the abundance of some phosphate solubilizing species.

62 Moreover, Rachid et al. (2015) reported that Eucalyptus intercropped with Acacia mangium

63 increased soil fungal community diversity and changed the fungal structure and Zheng et al.

64 (2018) reported that intercropping of apple trees and crown vetch changed the soil bacterial

65 structure but not diversity. In our study, the bacterial and fungal structure and activity in the

66 intercropping and monoculture system were analysed. We hypothesized that intercropping

67 improves soil properties, increases the microbial diversity, changes community structure and improves some microbial function (H1) and that change in microbial community will correlate with microbial activity $(\mathrm{H} 2)$.

\section{Materials and methods}

\subsection{Experimental design and plant materials}

The intercropping experiment was established in March of 2016 with three replicates of three treatments in a randomized block design. The treatments included (1) sugarcane monoculture, (2) soybean monoculture and (3) sugarcane intercropped with soybean. The soil used in this study was classified as Ali-Udic Argosol with pH 5.1, soil organic carbon (SOC) $8.5 \mathrm{~g} \mathrm{~kg}^{-1}, 0.41 \mathrm{~g} \mathrm{~kg}^{-1}$ total $\mathrm{N}$ and $0.42 \mathrm{~g} \mathrm{~kg}^{-1}$ total $\mathrm{P}$.

The sugarcane variety ROC22 (Saccharum officinarum) and soybean variety HuaChun5 
78 (Glycine max L.), which are widely grown in South China, were used in this study. Plants were

79 grown in pots in the glasshouse at South China Agriculture University, Guangzhou, China. In

80 brief, all plants within a pot (140 cm wide $\times 45 \mathrm{~cm}$ width $\times 45 \mathrm{~mm}$ high $)$ were filled with $30 \mathrm{~kg}$

81 of sieved soil $(<2 \mathrm{~mm})$ and considered as one replicate. Two sugarcane seedlings or three

82 soybean seeds were planted in a pot under the monoculture system, or two sugarcane seedlings

83 with three soybean seeds were planted under the intercropping system. The row space was $0.9 \mathrm{~m}$

84 for sugarcane and $0.3 \mathrm{~m}$ for soybean in all treatments. The water content of the soil was adjusted

85 to $80 \%$ of field water capacity. Plants were harvested at the flowering stage.

2.2. Soil sampling and measurements

87

Rhizosphere soil was recovered separately on May 25th, 2016 (40 days after sowing) by shaking root for 3 min into a bag and mix thoroughly. Contact between samples was avoided. Approximately $5 \mathrm{~g}$ soil from each treatment was collected and stored at $-80{ }^{\circ} \mathrm{C}$ for DNA extraction. Additionally, $100 \mathrm{~g}$ soil was collected and stored at $4{ }^{\circ} \mathrm{C}$ for analyses of microbial and soil physicochemical properties.

Soil $\mathrm{pH}$ was determined in a soil-water slurry (1:5 w:v) using a $\mathrm{pH}$ meter (FE20FiveEasy $^{\mathrm{TM}} \mathrm{pH}$, Mettler Toledo, German). Soil total nitrogen was measured using an elemental analyser (VarioEL III, Germany). Nitrate $\left(\mathrm{NO}_{3}^{-}\right)$and ammonium $\left(\mathrm{NH}_{4}{ }^{+}\right)$were assayed using a continuous flow analytical system (SKALAR SAN++, The Netherlands). Soil organic carbon (SOC), dissolved organic carbon (DOC), and dissolved organic nitrogen (DON) were measured using a TOC analyser (Multi N/C 2100, Analytik Jena, Germany). Soil microbial biomass carbon 
98 (MBC) and microbial biomass nitrogen (MBN) were measured by the chloroform-fumigation

99

100

101

102

103

104

105

106

107

108

109

110

111

112

113

114

115

116

\subsection{Soil incubation and respiration measurements}

The methods of the incubation experiment were reported in our previous study (Lian et al., 2016). In brief, $20 \mathrm{~g}$ soil was collected from each treatment and placed into PVC cores $(5 \mathrm{~cm}$ height, 2.5 cm diameter). The PVC core and a beaker with $10 \mathrm{ml} 1 \mathrm{M} \mathrm{NaOH}$, which used to trap $\mathrm{CO}_{2}$, were placed into a 0.5 - $\mathrm{L}$ sealed container. The trapped $\mathrm{CO}_{2}$ was precipitated with $0.5 \mathrm{M} \mathrm{SrCl}_{2}$ and $\mathrm{NaOH}$ was neutralized with $0.1 \mathrm{M} \mathrm{HCl}$. Soil respiration was estimated on $1,3,5,7,9,11,14,18$, 22, 26, 32, 39, 46, 53, and 60 days after incubation was initiated (Blagodatskaya et al. 2011).

\subsection{DNA extraction and quantitative PCR (qPCR)}

DNA was extracted using Fast DNA SPIN Kit for Soil (Qbiogene Inc., Carlsbad, CA, USA) according to the manufacturer's instructions. Quantitative PCR (qPCR) was conducted by targeting bacterial 16S rRNA genes and fungal ITS1 region, using the primers 515F/907R (Osburn et al., 2011) and ITS1F/ITS2R (Yao et al., 2017), respectively, following the protocols reported previously (Liu et al. 2015).

\subsection{Illumina MiSeq sequencing analysis}

Illumina MiSeq sequencing of the 16S rRNA genes and fungal ITS1 region was performed to examine the structure of the soil bacterial and fungal community, respectively. The raw 
117 sequences were processed and analysed using QIIME1 Pipeline Version 1.9.0. Multiple steps

118 were conducted to remove low-quality sequences with lengths shorter than 200 bp and quality

119 scores less than 20. For further analysis, the chimeric sequences were checked and removed

120 using UCHIME algorithm. High-quality sequences were clustered into operational taxonomic

121 units (OTUs) using RDP Classifier based on 97\% sequence similarity. The OTUs were analysed

122 using the SILVA and UNITE database for bacteria and fungi, respectively. Then, a phylogenetic

123 tree was built using Fast Tree (Price et al., 2009). For a correct comparison between samples,

124 rarefied subsequening numbers (14811 for bacterial and 29726 for fungi) were used for

125 subsequent analysis. All sequences have been deposited into the GenBank short-read archive

126 under accession SRP116883 (bacteria) and SRP129902 (fungi).

127 2.6. Statistical analysis

128 Using the program R (version 3.4.4, vegan package), principal coordinate analysis (PCoA) based

129 on OTU level was processed to assess the patterns of similarity (Bray-Curtis similarity) in the

130 composition of the microbial community between treatments. The Chao 1 index and Shannon

131 richness were calculated to compare soil bacterial and fungal alpha diversity (Fig. S1). A

132 canonical correspondence analysis (CCA) was conducted to reveal the association between soil

133 property variables and microbial community structure. Spearman correlation analysis was

134 conducted with SPSS 24.0 to identify correlation between microbial activity and structure.

135 PICRUSt analysis and STAMP were conducted to predict and visualize bacterial functional

136 profiling (Langille et al., 2013; Parks and Beiko, 2010). FUNGuild was used to identify fungi 
137 functional guilds (Nguyen et al., 2016).

138

139

140

141

142

143

144

145

146

147

148

149

150

151

152

153

154

155

ANOVA test was used with Genstat 13 (VSN International, Hemel Hemspstead, UK) to assess the effect of treatments on the SOC, total N, MBC, MBN, DOC, DON, $\mathrm{NH}_{4}{ }^{+}-\mathrm{N}, \mathrm{NO}_{3}{ }^{-}-\mathrm{N}$, $\mathrm{pH}$, and the relative abundance of OTU inferred with FUNGuild. Furthermore, ANOVA test of least significant difference (LSD) was used to assess the different of respiration rate and cumulative respiration. Differences were considered statistically significant at level of $p<0.05$. The ratios of microbial community carbon-use efficiency and nitrogen-use efficiency were calculated as follows (Mooshammer et al., 2014):

Carbon-use efficiency : Nitrogen-use efficiency $=\mathrm{B}_{\mathrm{C}: \mathrm{N}}: \mathrm{R}_{\mathrm{C}: \mathrm{N}}$ where $B_{C: N}$ is the $C: N$ ratio of the microbial community and $\mathrm{R}_{\mathrm{C}: \mathrm{N}}$ is the $\mathrm{C}: \mathrm{N}$ ratio of the soil.

\section{Results}

3.1 Effect of intercropping on soil physicochemical properties

Compared with monoculture treatments, intercropping decreased $\mathrm{pH}$ from 6.73 to 6.13 and from 5.97 to 5.45 for sugarcane and soybean, respectively. The SOC was higher in I-Sugarcane (intercropped sugarcane) and I-Soybean (intercropped soybean) than that in the M-Sugarcane (sugarcane monoculture) and M-Soybean (soybean monoculture). The concentration of SOC significantly increased under I-Sugarcane compared with that under M-Sugarcane. $\mathrm{NH}_{4}^{+}, \mathrm{DOC}$, DON, MBC, and MBN levels were significantly increased for the two plant species under intercropping compared with those for the monoculture $(p<0.05)$, while the $\mathrm{NO}_{3}{ }^{-}$level showed 
156 an opposite trend $(p<0.05)$ (Table 1$)$.

157 3.2. Effect of intercropping on microbial activity

158 Soil respiration was enhanced in the intercropping system (Fig. 1). Respiration peaked on day 159 one and then decreased exponentially; respiration did not differ significantly between treatments

160 (Fig. 1a). During the incubation, the cumulative $\mathrm{CO}_{2}-\mathrm{C}$ levels were $6.9 \%$ and $5.3 \%$ greater in the 161 intercropping soil than those in the monoculture for sugarcane and soybean, respectively (Fig. 162 1b). Moreover, the I-Sugarcane and I-Soybean treatments showed higher ratios of carbon- and 163 nitrogen-use efficiency than that for the M-Sugarcane and M-Soybean, respectively (Fig. 1c).

Intercropping significantly increased bacterial and fungal abundances in sugarcane. However, no significant difference was observed in the fungi : bacteria (F : B) ratios (Fig. 2). Moreover, intercropping increased Chao index of bacteria and fungi; however, significant higher Shannon richness was only observed in I-Soybean compared with M-Soybean (Fig. S1d). PCoA analysis showed that the bacterial and fungal communities from different treatments were clearly separated from each other (Fig. S2), which indicates crop species and culture mode influenced the soil microbial community. The dominant phyla, Proteobacteria, Chloroflexi, Acidobacteria, Actinobacteria and Firmicutes for bacteria and Ascomycota, Zygomycota and Basidiomycota for fungi, were the same across treatments (Fig. 3).

CCA analysis (Fig. 4) revealed a relationship between microbial community structure and 
176 fungal community, respectively. The soil $\mathrm{pH}, \mathrm{SOC}, \mathrm{NO}_{3}{ }^{-}, \mathrm{DOC}, \mathrm{MBC}$, and $\mathrm{MBN}(p=0.04,0.01$,

$1770.03,0.008,0.02$, and 0.004, respectively, for the bacterial community; $p=0.001,0.04,0.04$,

$1780.01,0.003$, and 0.02 for the fungal community) appeared to be strongly correlated with the

179 microbial community.

The X-axis of the PCoA analysis of bacteria and fungi (Fig. S2) was used in the Spearman correlation analysis to detect the relationships between microbial activity and structure (Table 2).

A significant relationship was observed between bacterial community and microbial activity;

however, the fungal community was not significantly correlated with bacterial communities and

microbial activity.

\subsection{Effect of intercropping on microbial functional characteristics}

186

187

Bacterial function predictions were categorized into KEEG pathways. In brief, pathways for nutrient cycles such as carbon fixation pathways in prokaryotes and citrate cycle (TCA cycle) significant increased, while lipid metabolism, sulfur metabolism and signal transduction mechanisms significant decreased in both I-Sugarcane and I-Soybean (Fig. 5, Table S1). For fungal function, 12 fungal functional guilds, such as wood saprotroph, plant pathogen, plant saprotroph, fungal parasite and endophyte were detected (Fig. 6a). Among the top 5 fungal functional guilds, the relative abundances of wood saprotroph significant increased in ISugarcane, and plant pathogen significant increased in I-Soybean (Table S2).

From the library generated with the ITS primer pair, more than 40 OTUs were detected and assigned to the functional group of wood saprotrophs. The top 4 OTUs belonged to the phylum 
196 Ascomycota, with relative abundance ranged from $6.21 \%$ to $18.38 \%$ (Table S3). Of these, the 197 relative abundances of OTU133 (Trichoderma) in I-Sugarcane were significantly higher than M198 Sugarcane. Relative abundances of OTU1092 (Aspergillus) and OUT126 (Acremonium) were 199 significantly higher in both I-Sugarcane and I-Soybean (Fig. 6b). For the functional group of 200 plant pathogen, the top 4 OTUs were belonged to the phylum Ascomycota. Among them, 201 relative abundances of OTU745 (Gibberella), OTU1092 (Clonostachys) and OUT126 202 (Gibellulopsis) were general lower in intercropping system. Nevertheless, the relative abundance of OTU941 (Gibellulopsis) was significantly higher in both I-Sugarcane and I-Soybean (Fig. 6c, Table S4).

\section{Discussion} fungal abundances and diversity, which is consistent with several previous studies (Sun et al., 2009; Kaur et al., 2000; Li et al, 2016). For soils collected from the intercropping or monoculture systems, nutrients and respiration decreased markedly from initial rates, which agrees with earlier studies (Lian et al., 2016) and the improvements in soil quality associated with intercropping appeared temporary. The higher respiration rates in the intercropped system could

213 relate to nitrogen fixation by the legume, which may have stimulated soil respiration of the 214 intercropped sugarcane (Qin et al., 2013). Higher bacterial and fungal abundances and diversity 215 may reflect the direct contact of crop roots in the intercropping system which stimulates roots to 
216 release more nutrients (Song et al., 2007). Environmental factors, such as pH and SOC, often

217 play important roles in shaping microbial community composition and diversity (Hartman et al.,

218 2008; Tripathi et al., 2018; Ma et al., 2018). Soil pH influences the acid-base equilibrium of

219 microbial cells or regulates the availability of soil nutrients (Zhalnina et al. 2015). In this study,

220 soil $\mathrm{pH}$ in intercropped soybean soils decreased compared with that in monoculture soil.

221 Additionally, CCA showed $\mathrm{pH}$ strongly correlated with $(p=0.04$ and $p=0.001$, for the bacterial

222 and fungal community, respectively) the microbial community. Together, our data indicates that

$223 \mathrm{pH}$ governed the microbial community.

224 SOC can also determine microbial community structure in natural environments (Sul et al., 2013;

225 Ma et al., 2018), as increased SOC favors copiotrophes (Fierer et al., 2012; Waring et al., 2013;

226 Luo et al., 2018). In this study, the significant increased SOC in intercropping system and the

227 significant correlation $(p=0.01$ and $p=0.04$, for the bacterial and fungal community, 228 respectively) between SOC and microbial community (Table 1 and Fig. 4) indicate that SOC 229 shaped the structure of microbial community. $\mathrm{NO}_{3}^{-}, \mathrm{DOC}, \mathrm{MBC}$, and $\mathrm{MBN}$ may also have 230 significant impact on the shift of microbial community structure (Fig. 4). Shifting nutrients 231 changes microbial communities (Sun et al., 2015; Ramirez et al., 2010), since increases in 232 available substrates might increase the activity of copiotrophs in soil (Fierer et al., 2012).

\section{4.2. Effect of intercropping on microbial activity}

234 Carbon-use efficiency, which can be calculated as $\mathrm{C}_{\text {growth }} /\left(\mathrm{C}_{\text {growth }}+\mathrm{C}_{\text {respiration }}\right)$ has a positive 235 correlation with microorganism growth and a negative correlation with respiration rates (Spohn 
236 et al., 2016). The increased microbial abundance, without a change in available N, may explain

237 the increase in carbon-use efficiency and not much change in nitrogen-use efficiency. Therefore,

238 the increased ratios of carbon- and nitrogen-use efficiency in this study may be caused by

239 carbon-use efficiency. However, respiration and the ratios of carbon- and nitrogen-use efficiency,

240 which represent the microbial activity, both increased in the intercropping system in this research.

241 This may be correlated with the nonlinear relationship between microbial growth and respiration

242 (Sinsabaugh et al., 2013). There have many other factors that affect the carbon-use efficiency

243 such as environmental constraints and resource (Sinsabaugh et al., 2013).

244 Carbon-use efficiency is positively correlated with nutrient availability. Bacterial carbon-use

245 efficiency tends to increase more markedly with nutrient availability than that with fungi

246 (Keiblinger et al., 2010), as bacteria and fungi are usually considered copiotrophic (r-selected)

247 and oligotrophic (K-selected) groups (Geyer et al., 2016). Additionally, the ratio of fungi and

248 bacteria might shift soil microbial community carbon-use efficiency (Sinsabaugh et al., 2013). In

249 our research, the abundance of bacteria and fungi were significant higher in the I-Soybean

250 system. However, the fungi : bacteria ratio did not differ among treatments. Together, more

251 bacteria and fungi abundance and the improved nutrient availability, such as SOC and DOC, in

252 intercropping system may lead to an increase carbon-use efficiency, which subsequently

253 increased the ratios of carbon-use efficiency and nitrogen-use efficiency. Additionally, better

254 nutrient availability in the plant-soil-microbial system could improve the plant growth. The

255 subsequent release of exudates increases soil microbial activity (Zhong et al., 2015; Levy et al., 
256 2018).

257 4.3. The relationship between microbial activity and microbial structure

258 The changed microbial community structure may result in increased microbial activity in the 259 intercropping system. Analysing dozens of species soil samples from a wide range of ecosystems

260 across America, Fierer et al. (2007) generalized that C mineralization predicts bacterial phyla

261 abundances. Thus, we assumed that the changed microbial activity may be caused by the shift in

262 the structure of microorganisms. The correlation between the microbial activity and community

263 structure showed that the bacterial community was significantly correlated with ratios of carbon-

264 and nitrogen-use efficiency and respiration. However, this significant correlation was not

265 observed with the fungal community, which may be attributed to bacteria were hundred times

266 more abundance than fungi (Fig. 2). Therefore, compared to bacteria, the changed fungal

267 community might have a less effect on microbial activity. Nevertheless, the dormancy rates of

268 bacteria are generally higher than fungi (Jones and Lennon 2010). When the dormancy rate

269 reaches a certain level, the quantitative advantage of bacteria cannot explain the high microbial

270 activity and this requires further verification and research. In this study, $\mathrm{pH}, \mathrm{NO}_{3}^{-}, \mathrm{MBN}$, and

271 SOC play important roles in the change in community structure. Our findings indicate that

272 intercropping altered the availability of carbon in the soil. The changed nutrient subsequently

273 allowed bacteria to affect the carbon- and nitrogen-use efficiency of the microorganisms.

274 4.4. Effect of intercropping on soil functional microorganisms

275 In general, the prediction of functional microorganisms matched well with our expectations. 
276 Functions such as carbon fixation pathways in prokaryotes, citrate cycle (TCA cycle) of bacteria

277 and wood saprotrophs of fungi were higher in the intercropping system. In contrast, plant

278 pathogens were slightly lower in the intercropping system. The result indicated that the

279 overrepresented functions in intercropping system potentially leading to an accumulation of

280 metabolic products and nutrients. For example, the increased carbon fixation pathways in

281 prokaryotes and citrate cycle (TCA cycle) suggested an acceleration of nutrient conversion (Shi

282 et al. 2017), which might be trigged by the increased microbial activity. Furthermore, the

283 increased OTU133 (Trichoderma) belong to wood saprotrophs in intercropped sugarcane may

284 control a wide range of phytopathogens because Trichoderma secretes chitinases and cellulases,

285 which can hydrolyse pathogen cell walls (Bae et al., 2015).

\section{5. Conclusions}

287 In conclusion, sugarcane-soybean intercropping in acidic soil increased microbial diversity and

288 shifted soil microbial communities and soil physicochemical properties $\left(\mathrm{pH}, \mathrm{SOC}, \mathrm{NO}_{3}^{-}, \mathrm{DOC}^{\text {, }}\right.$

$289 \mathrm{MBC}$ and $\mathrm{MBN}$ ). The changed bacterial community correlated to higher soil respiration rates

290 and nutrient use efficiency. Furthermore, intercropping influenced microbial functions, such as

291 carbon fixation pathways in prokaryotes, citrate cycle (TCA cycle) of bacteria and wood

292 saprotrophs of fungi. These overrepresented functions may accelerate nutrient conversion and

293 control phytopathogens in soil.

\section{References}

295 Bae SJ, Mohanta TK, Chung JY, Ryu M, Park G, Shim S. 2015. Trichoderma metabolites 
296

297

298

299

300

301

302

303

304

305

306

307

308

309

310

311

312

313

314

control phytopathogens of phytophthora blight. Biological Control 92: 128-138.

Blagodatskaya E, Yuyukina T, Blagodatsky S, and Kuzyakov Y. 2011. Turnover of soil organic matter and of microbial biomass under $\mathrm{C} 3-\mathrm{C} 4$ vegetation change: consideration of ${ }^{13} \mathrm{C}$ fractionation and preferential substrate utilization. Soil Biology and Biochemistry 43:159-166 DOI: $10.1016 / j$.soilbio.2010.09.028.

Broeckling CD, Broz AK, Bergelson J. Manter DK. 2008. Root exudates regulate soil fungal community composition and diversity. Applied and Environmental Microbiology 74: 738-744, DOI:10.1128/AEM.02188-07.

Brookes PC, Landman A, Pruden G, Jenkinson D. 1985. Chloroform fumigation and the release of soil nitrogen: a rapid direct extraction method to measure microbial biomass nitrogen in soil. Soil Biology and Biochemistry 17: 837-842 DOI: 10.1016/0038-0717(85)90144-0.

Fierer N, Bradford MA, and Jackson RB. 2007. Toward an ecological classification of soil bacteria. Ecology 88: 1354-1364.

Fierer N, Lauber CL, Ramirez KS, Zaneveld J, Bradford MA, Knight R. 2012. Comparative metagenomic, phylogenetic and physiological analyses of soil microbial communities across nitrogen gradients. The ISME Journal 6: 1007-1017.

Geyer KM, Kyker-Snowman E, Grandy AS, Frey SD. 2016. Microbial carbon use efficiency: accounting for population, community, and ecosystem-scale controls over the fate of metabolized organic matter. Biogeochemistry 127: 173-188 DOI: 10.1007/s10533-016-0191-y. 
315 Gomes NCM, Fagbola O, Costa R, Rumjanek NG, Buchner A, Mendona-Hagler L, Smalla K. 316 2003. Dynamics of fungal communities in bulk and maize rhizosphere soil in the tropics.

317 Applied and Environmental Microbiology 69: 3758-3766 DOI: 10.1128/AEM.69.7.37583183766.2003.

319 Hartman WH, Richardson CJ, Vilgalys R, Bruland GL. 2008. Environmental and anthropogenic 320 controls over bacterial communities in wetland soils. Proceedings of the National Academy of 321 Sciences 105: 17842-17847 DOI: 10.1073/pnas.0808254105.

322 He JF, Huang GQ, Liao P, Liu XY, Su YH. 2006. Effects on disaster reduction of maize/soybean 323 intercropping ecological system on upland red soil. Meteorology and Disaster Reduction 324 Research 29: 31-35 (in Chinese).

325 Jones SE, Lennon JT. 2010. Dormancy contributes to the maintenance of microbial diversity. 326 Proceedings of the National Academy of Sciences 107: 5881-5886. DOI: 327 10.1073/pnas.0912765107.

328 Kaur B, Gupta SR and Singh G. 2000. Soil carbon, microbial activity and nitrogen availability in 329 agroforestry systems on moderately alkaline soils in northern India. Applied Soil Ecology 15: 330 283-294 DOI: 10.1016/S0929-1393(00)00079-2.

331 Keiblinger KM, Hall EK, Wanek W, Szukics U, H€ ammerle I, Ellersdorfer G, Bock S, Strauss J, 332 Sterflinger K, and Richter, A. 2010. The effect of resource quantity and resource stoichiometry 333 on microbial carbon-use-efficiency. FEMS Microbiology Ecology 73: 430-440 DOI: 
335

336

337

338

339

340

341

342

343

344

345

346

347

348

349

350

351

352

Langille MGI., Zaneveld J, Caporaso JG, McDonald D, Knights D, Reyes JA, Clemente JC, Burkepile DE., Thurber RLV., Knight R, Beiko RG, Huttenhower C. 2013. Predictive functional profiling of microbial communities using $16 \mathrm{~S}$ rRNA marker gene sequences. Nature Biotechnology 31: 814-821. DOI: 10.1038/nbt.2676.

Levy A, Salas IG, Mittelviefhaus M, Clingenpeel S, Herrera S P, Miao J, Wang K, Devescovi G, Stillman K, Monteiro M, Alvarez BR, Lundberg DS, Lu TY, Lebeis S, Jin Z, McDonald M, Klein AP, Feltcher ME, Rio TG, Grant SR, Doty SL, Ley RE, Zhao BY, Venturi V, Pelletier DA, Vorholt JA, Tringe SG, Woyke T, Dangl JL. 2018. Genomic features of bacterial adaptation to plants. Nature Genetics, 50: 138.DOI: 10.1038/s41588-017-0012-9.

Li X, Mu Y, Cheng Y, Liu X and Nian H. 2013. Effects of intercropping sugarcane and soybean on growth, rhizosphere soil microbes, nitrogen and phosphorus availability. Acta Physiologiae Plantarum 35:1113-1119 DOI: 10.1007/s11738-012-1148-y.

Li X, Sun M, Zhang, H, Xu N, and Sun G. 2016. Use of mulberry-soybean intercropping in saltalkali soil impacts the diversity of the soil bacterial community. Microbial Biotechnology 9: 293304 DOI: 10.1111/1751-7915.12342.

Lian T, Wang G, Yu Z, Li YS, Liu XB and Jin J. 2016. Carbon input from ${ }^{13}$ C-labelled soybean residues in particulate organic carbon fractions in a Mollisol. Biology and Fertility of Soils 52: 331-339 DOI: 10.1007/s00374-015-1080-6. 
353 Liu JJ, Sui YY, Yu ZH, Shi Y, Chu HY, Jin J, Liu XB, Wang GH. 2015. Soil carbon content

354 drives the biogeographical distribution of fungal communities in the black soil zone of northeast

355 China. Soil Biology and Biochemistry 83: 29-39 DOI: 10.1016/j.soilbio.2015.01.009.

356 Luo S, Wang S, Tian L, Shi S, Xu S, Yang, F., Li X, Wang Z, Tian C. 2018. Aggregate-related

357 changes in soil microbial communities under different ameliorant applications in saline-sodic

358 soils. Geoderma 329: 108-117. DOI: 10.1016/j.geoderma.2018.05.023.

359 Ma B, Lv X, Cai Y, Chang SX, Dyck MF. 2018. Liming does not counteract the influence of 360 long-term fertilization on soil bacterial community structure and its co-occurrence pattern. Soil 361 Biology and Biochemistry 123: 45-53. DOI: 10.1016/j.soilbio.2018.05.003.

362 Maciávicente JG, Rosso LC, Ciancio A, Jansson HB and Lopezllorca LV. 2009. Colonisation of 363 barley roots by endophytic fusarium equiseti and pochonia chlamydosporia: effects on plant 364 growth and disease. Annals of Applied Biology 155: 391-401 DOI: 10.1111/j.1744365 7348.2009.00352.x.

366 Mooshammer, M., Wanek, W., Hammerle, I., Fuchslueger, L., Hofhansl, F., € Knoltsch, A., 367 Schnecker J, Takriti M, Watzka M and Wild B. 2014. Adjustment of microbial nitrogen use 368 efficiency to carbon: nitrogen imbalances regulates soil nitrogen cycling. Nature 369 Communications 5: 3694 DOI: 10.1038/ncomms4694.

370 Nguyen NH, Song Z, Bates ST, Branco S, Tedersoo L, Menke J, Schilling JS, Kennedy PG. 371 2016. FUNGuild: An open annotation tool for parsing fungal community datasets by ecological 
372 guild. Fungal Ecology 20: 241-248. DOI: 10.1016/j.funeco.2015.06.006.

373 Osburn MR, Sessions AL, Pepe-Ranney C, Spear JR. 2011. Hydrogen-isotopic variability in 374 fatty acids from Yellowstone National Park hot spring microbial communities. Geochimica et 375 Cosmochimica Acta 75: 4830-4845 DOI: 10.1016/j.gca.2011.05.038.

376 Parks DH and Beiko RG. 2010. Identifying biologically relevant differences between 377 metagenomic communities. Bioinformatics 26: 715-721. DOI: 10.1093/bioinformatics/btq041.

378 Price MN, Dehal PS, Arkin AP. 2009. Fast Tree: computing large minimum evolution trees with 379 profiles instead of a distance matrix. Molecular Biology and Evolution 26: 1641-1650. DOI: $380 \quad 10.1093 / \mathrm{molbev} / \mathrm{msp} 077$.

381 Qin AZ, Huang GB, Chai Q, Yu AZ, Huang P. 2013. Grain yield and soil respiratory response to 382 intercropping systems on arid land. Field Crops Research 144: 1-10. DOI: 383 org/10.1016/j.fcr.2012.12.005.

384 Rachid CTCC, Balieiro FC, Fonseca ES, Peixoto RS, Chaer GM, Tiedje JM, Rosado AS. 2015. 385 Intercropped silviculture systems, a key to achieving soil fungal community management in 386 Eucalyptus plantations. PloS one 10: e0118515 DOI: org/10.1371/journal.pone.0118515.

387 Ramirez KS, Lauber CL, Knight R, Bradford MA, Fierer N. 2010. Consistent effects of nitrogen 388 fertilization on soil bacterial communities in contrasting systems. Ecology, 91: 3463-3470. DOI: 389 $10.1890 / 10-0426.1$ 
391

392

393

394

395

monoculture and hedgerow intercropping in the humid tropics. Plant and Soil 268: 61-74 DOI: $10.1007 / \mathrm{s} 11104-004-0227-2$.

Shi L, Huang Y, Zhang M, Yu Y, Lu Y, Kong F. 2017. Bacterial community dynamics and functional variation during the long-term decomposition of cyanobacterial blooms in-vitro. Science of the Total Environment 598: 77-86. DOI: 10.1016/j.scitotenv.2017.04.115.

Sinsabaugh RL, Manzoni S, Moorhead DL, Richter A. 2013. Carbon use efficiency of microbial communities: stoichiometry, methodology and modelling. Ecology Letters 16: 930-939. DOI: 10.1111/ele.12113.

Song YN, Marschner P, Li L, Bao XG, Sun JH and Zhang FS. 2007. Community composition of ammonia-oxidizing bacteria in the rhizosphere of intercropped wheat (Triticum aestivum L.), maize (Zea mays L.), and faba bean (Vicia faba L.). Biology and Fertility of Soils 44:307-314 DOI: 10.1007/s00374-007-0205-y.

Spohn M, Klaus K, Wanek W, Richter A. 2016. Microbial carbon use efficiency and biomass turnover times depending on soil depth - Implications for carbon cycling. Soil Biology and Biochemistry 96, 74-81. DOI: 10.1016/j.soilbio.2016.01.016.

Sul WJ, Asuming-Brempong S, Wang Q, Tourlousse DM, Penton CR, Deng Y, Rodrigues J.L., Adiku SG, Jones JW and Zhou J. 2013. Tropical agricultural land management influences on soil microbial communities through its effect on soil organic carbon. Soil Biology and Biochemistry 65: 33-38 DOI: 10.1016/j.soilbio.2013.05.007. 
410 Sun R, Zhang XX, Guo X, Wang D, Chu H. 2015. Bacterial diversity in soils subjected to long-

411 term chemical fertilization can be more stably maintained with the addition of livestock manure

412 than wheat straw. Soil Biology and Biochemistry 88: 9-18. DOI: 10.1016/j.soilbio.2015.05.007.

413 Sun YM, Zhang NN, Wang ET, Yuan HL, Yang JS and Chen WX. 2009. Influence of

414 intercropping and intercropping plus rhizobial inoculation on microbial activity and community

415 composition in rhizosphere of alfalfa (Medicago sativa L.) and Siberian wild rye (Elymus

416 sibiricus L.). FEMS Microbiology Ecology 70: 218-226 DOI: 10.1111/j.1574-

$417 \quad 6941.2009 .00752 . x$.

418 Tripathi BM, Stegen JC, Kim M, Dong K, Adams JM and Lee YK. 2018. Soil pH mediates the

419 balance between stochastic and deterministic assembly of bacteria. ISME Journal 12 DOI:

$420 \quad 10.1038 / \mathrm{s} 41396-018-0082-4$.

421 Vance E, Brookes P and Jenkinson D. 1987. An extraction method for measuring soil microbial

422 biomass C. Soil Biology and Biochemistry 19: 703-707 DOI: 10.1016/0038-0717(87)90052-6.

423 Waring BG, Averill C, Hawkes CV. 2013. Differences in fungal and bacterial physiology alter

424 soil carbon and nitrogen cycling: insights from meta-analysis and theoretical models. Ecology

425 Letters 16: 887-894 DOI: 10.1111/ele.12125.

$426 \mathrm{Xu}$ BC, Li FM and Shan L. 2008. Switchgrass and milkvetch intercropping under 2:1 row-

427 replacement in semiarid region: northwest China: aboveground biomass and water use efficiency.

428 European Journal of Agronomy 28:485-492 DOI: 10.1016/j.eja.2007.11.011. 
429 Yao Q, Liu J, Yu Z, Li Y, Jin J, Liu X and Wang GH. 2017. Three years of biochar amendment 430 alters soil physiochemical properties and fungal community composition in a black soil of 431 northeast china. Soil Biology and Biochemistry 110: 56-67 DOI: 10.1016/j.soilbio.2017.03.005.

432 Zhalnina K. Dias R, Quadros PDD, Davis-Richardson A, Camargo FAO, Clark IM, McGrath SP, 433 Hirsch PR, Triplett EW. 2015.Soil pH determines microbial diversity and composition in the 434 park grass experiment. Microbial Ecology 69: 395-406 DOI: 10.1007/s00248-014-0530-2.

435 Zheng W, Gong Q, Zhao Z, Liu J, Zhai B, Wang Z, Li Z. 2018. Changes in the soil bacterial 436 community structure and enzyme activities after intercrop mulch with cover crop for eight years 437 in an orchard. European Journal of Soil Biology 86, 34-41. DOI: 10.1016/j.ejsobi.2018.01.009.

438 Zhong $\mathrm{Y}$, Yan $\mathrm{W}$ and Shangguan Z. 2015. Impact of long-term N additions upon coupling 439 between soil microbial community structure and activity, and nutrient-use efficiencies. Soil 440 Biology and Biochemistry 91:151-159 DOI: 10.1016/j.soilbio.2015.08.030.

441 Zhou X, Yu G and Wu F. 2011. Effects of intercropping cucumber with onion or garlic on soil 442 enzyme activities, microbial communities and cucumber yield. European Journal of Soil Biology 443 47: 279-287 DOI: 10.1016/j.ejsobi.2011.07.001. 


\section{Figure 1}

Respiration rates, cumulative respiration and the ratios of carbon-use efficiency and nitrogen-use efficiency

Respiration rates (a) and cumulative respiration (b) each treatment and the ratios of carbonuse efficiency and nitrogen-use efficiency (c). M-Sugarcane, sugarcane monoculture; ISugarcane, intercropped sugarcane. M-Soybean, soybean monoculture; I-Soybean, intercropped soybean. 

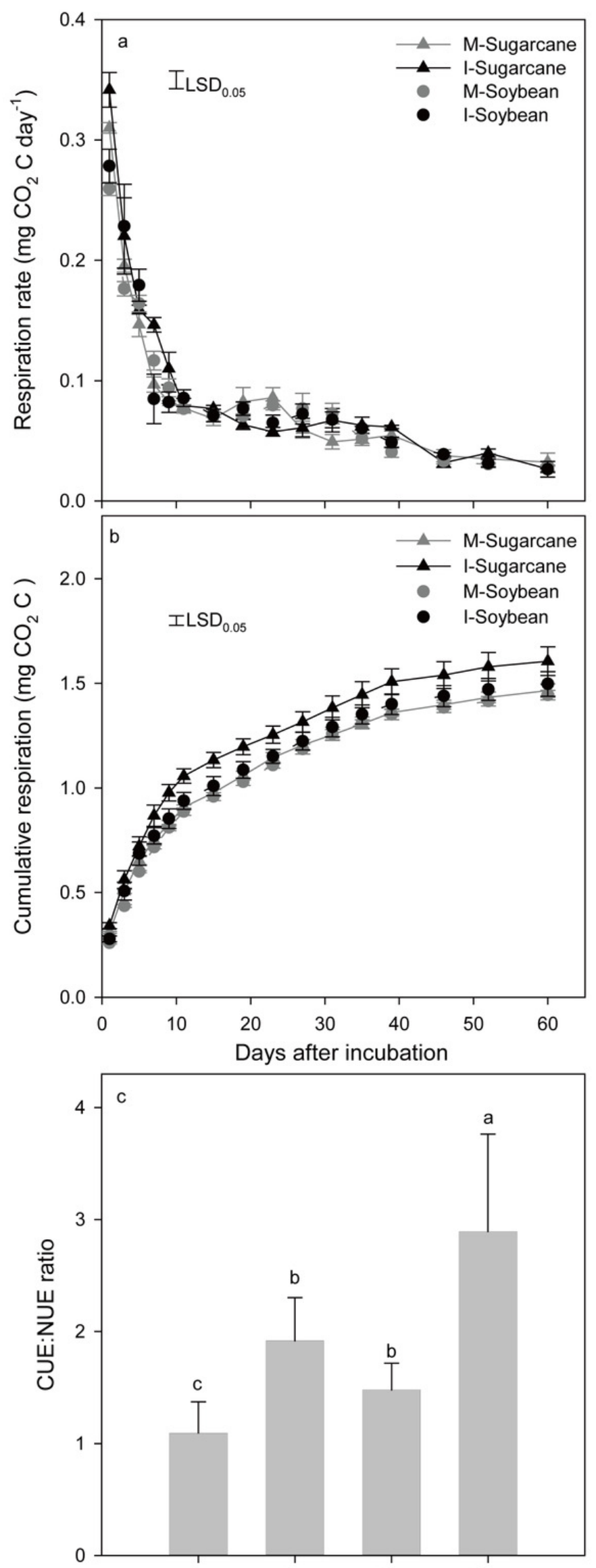

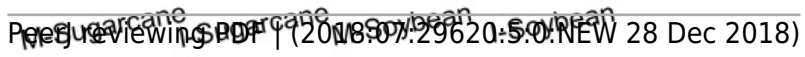




\section{Figure 2}

Bacterial and fungal abundances, and the relative ratio of the fungi and bacteria

Bacterial abundances (a) and fungal abundances (b) and relative ratio of the fungi and bacteria (c) in each treatment. M-Sugarcane, sugarcane monoculture; I-Sugarcane, intercropped sugarcane. M-Soybena, soybean monoculture; I-Soybean, intercropped soybean. 

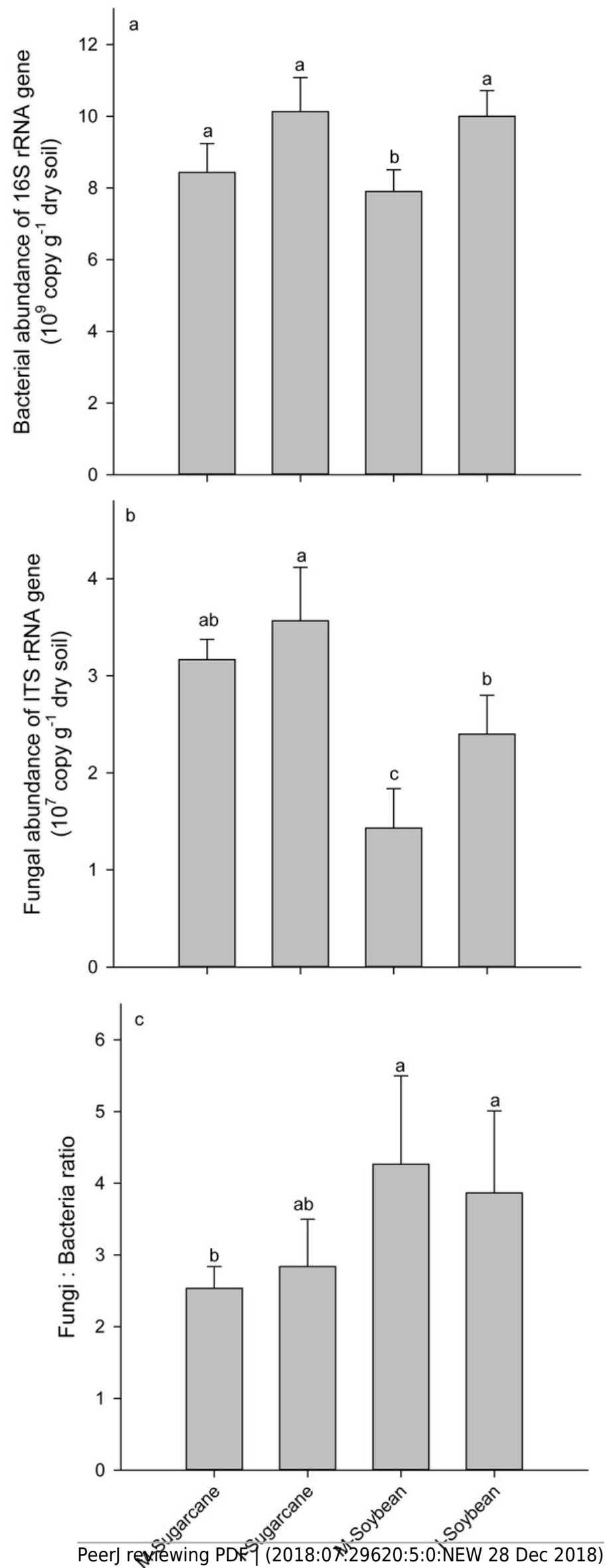


\section{Figure 3}

Relative abundance of bacterial and fungal phyla

Phylogenetic relationships of bacterial (a) and fungal (b) communities shown with the relative abundances of different phyla. M-Sugarcane, sugarcane monoculture; I-Sugarcane, intercropped sugarcane. M-Soybean, soybean monoculture; I-Soybean, intercropped soybean.

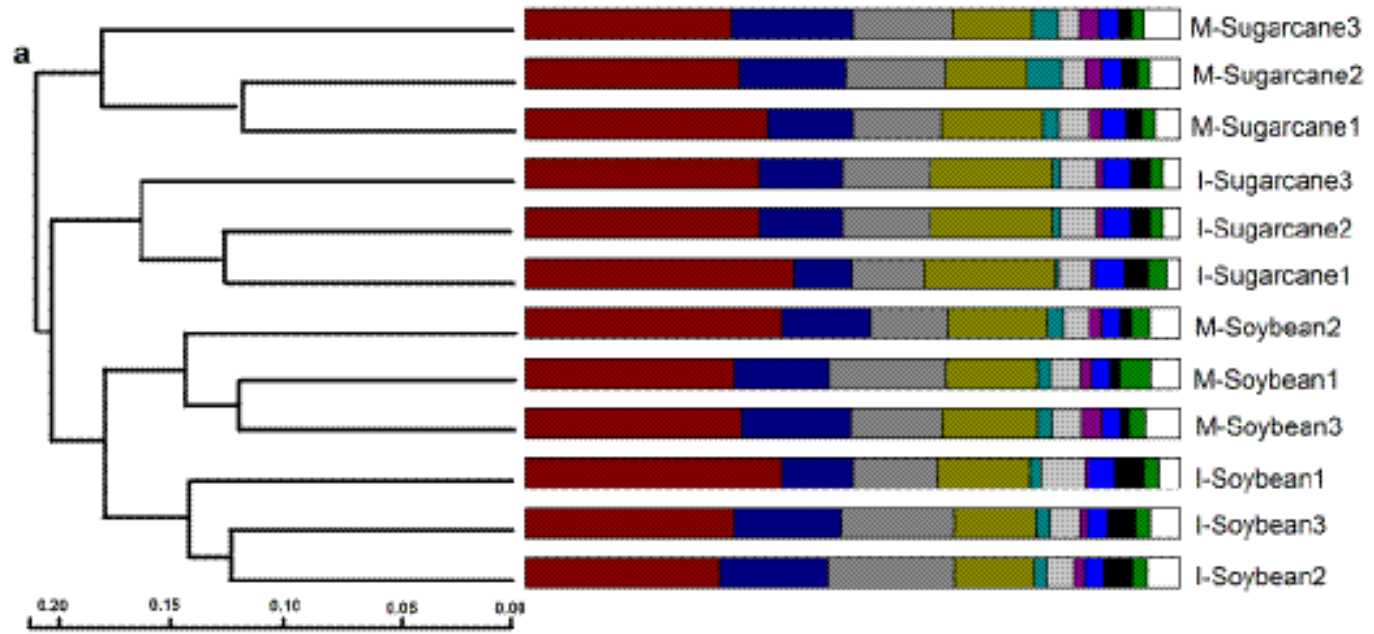

Proteobacteria Acidobacteria Chloroflexi Actinobacteria Cyanobacterian Firmicutes

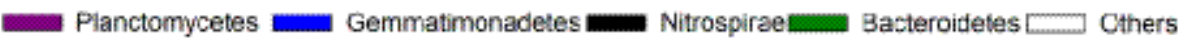

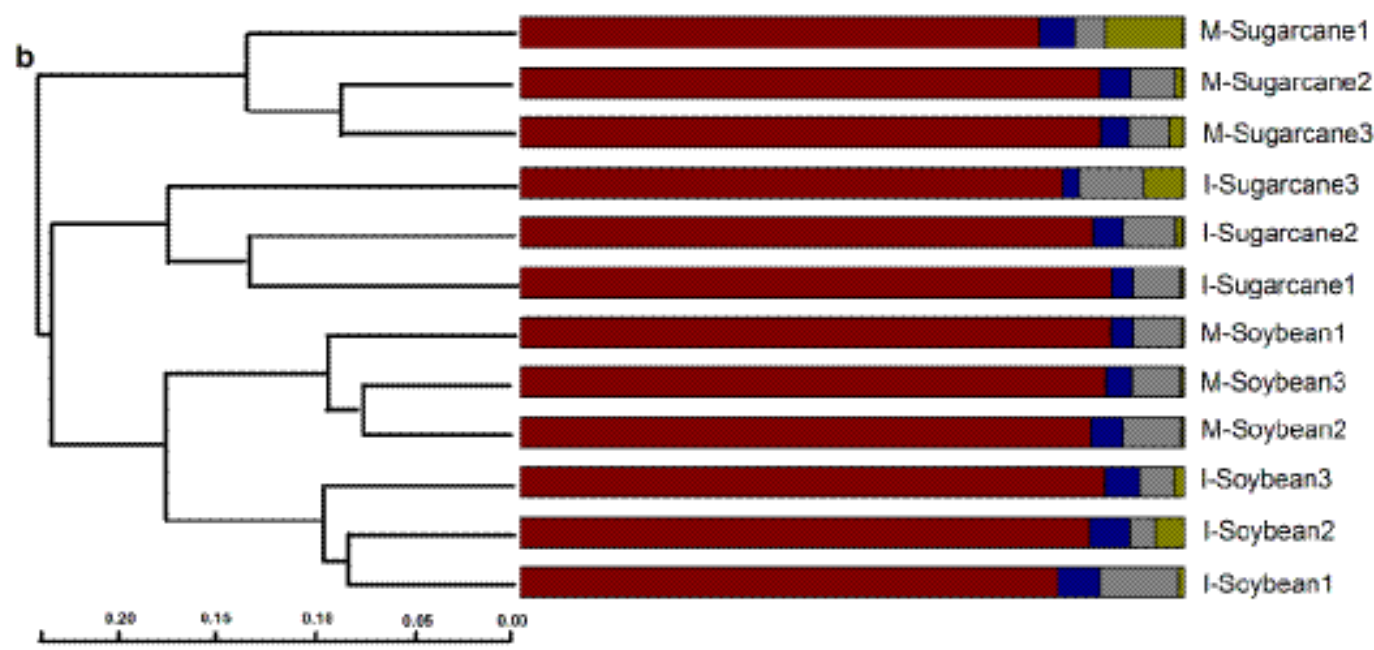




\section{Figure 4}

Canonical correspondence analysis (CCA) of bacterial and fungal communities

Canonical correspondence analysis (CCA) of bacterial and fungal communities Canonical correspondence analysis (CCA) of bacterial (a) and fungal (b) communities changes with environmental variables M-Sugarcane, sugarcane monoculture; I-Sugarcane, intercropped sugarcane. M-Soybean, soybean monoculture; I-Soybean, intercropped soybean.
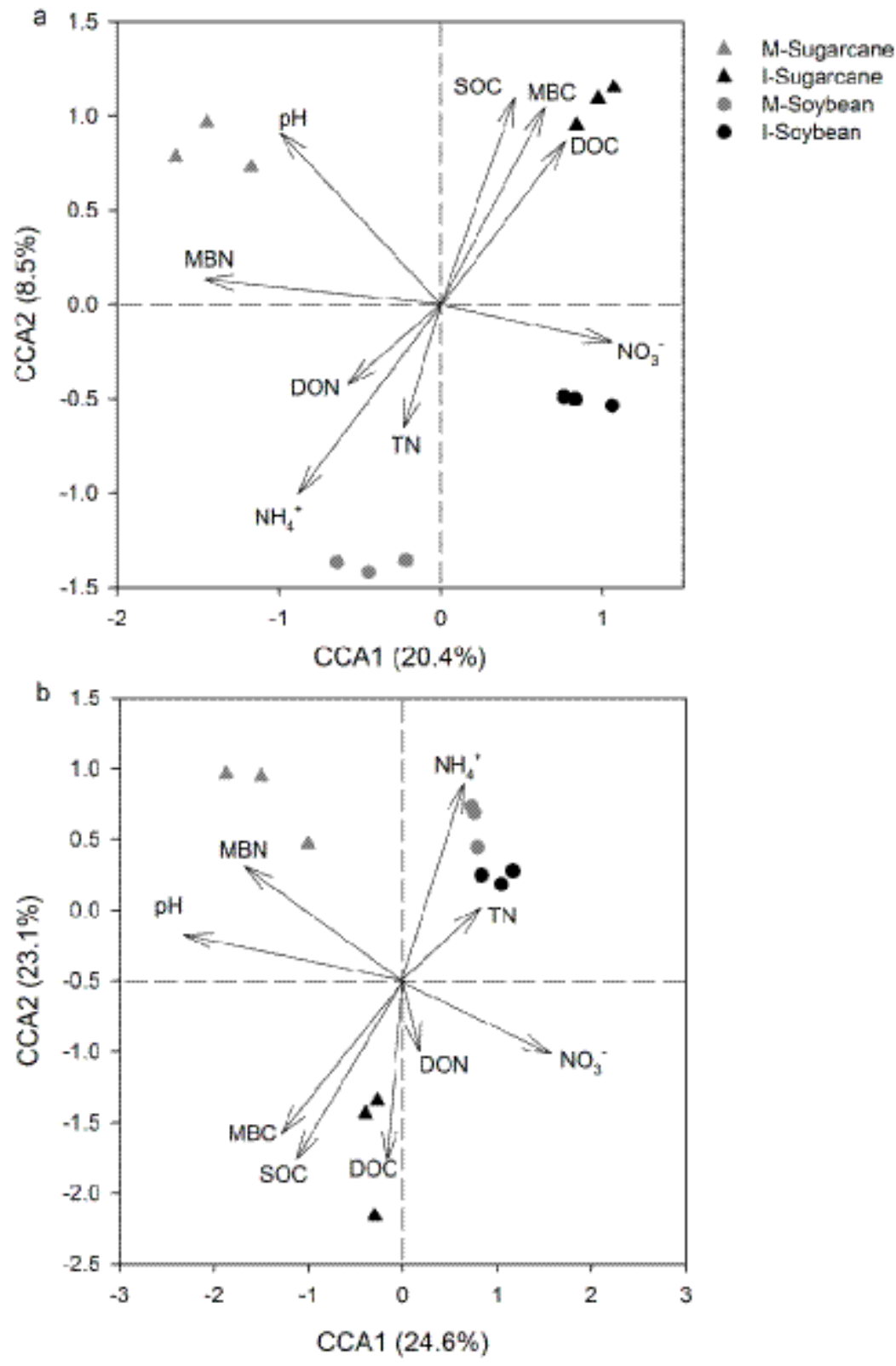


\section{Figure 5}

\section{Relative abundance of predicted soil bacterial functions}

Relative abundance of predicted soil bacterial functions in sugarcane (a) and soybean (b)

system predicted by PICRUSt using KEGG Orthologs. Pathways presented here are relevant to

soil ecosystem function, full data supplied in Table S1. I-Sugarcane, intercropped sugarcane.

M-Soybean, soybean monoculture; I-Soybean, intercropped soybean.

a

M-Sugarcane $\square$ I-Sugarcane

Arachidonic acid metabolism 日

Sulfur metabolism

Carbon fixation pathways in prokaryotes

Signal transduction mechanisms

Citrate cycle (TCA cycle)

Bacterial motility proteins

Lipid metabolism

Secretion system

$\mathrm{b}$
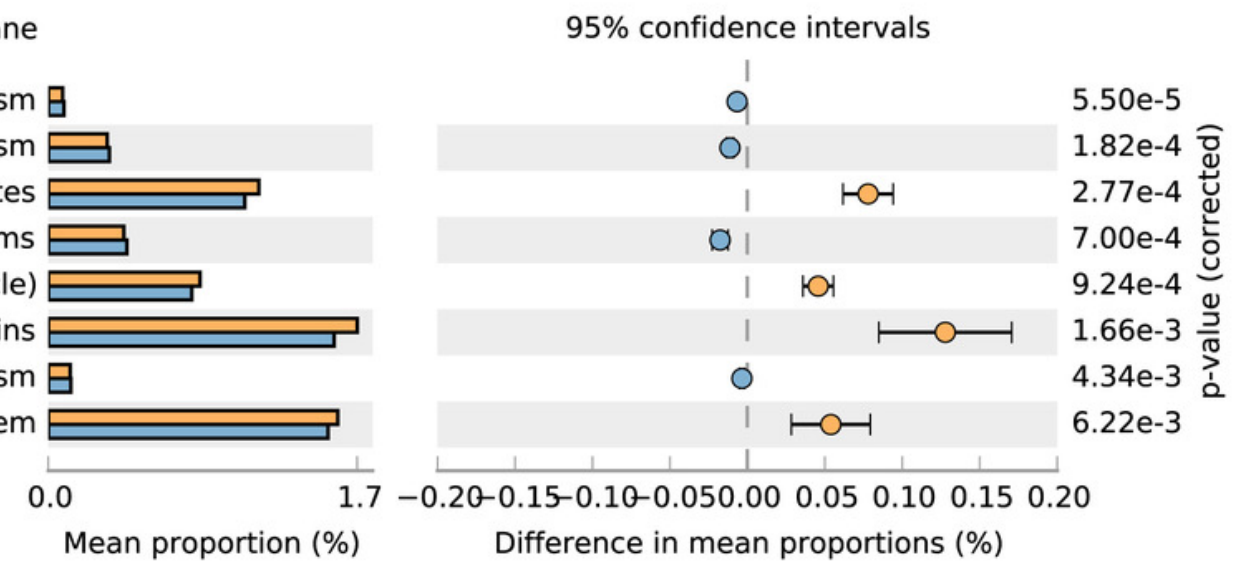

$\square$ M-Soybean

I-Soybean

Carbon fixation pathways in prokaryotes Citrate cycle (TCA cycle) Lipid metabolism Signal transduction mechanisms Sulfur metabolism Bacterial secretion system Mean proportion (\%)

Difference in mean proportions (\%)

$95 \%$ confidence intervals
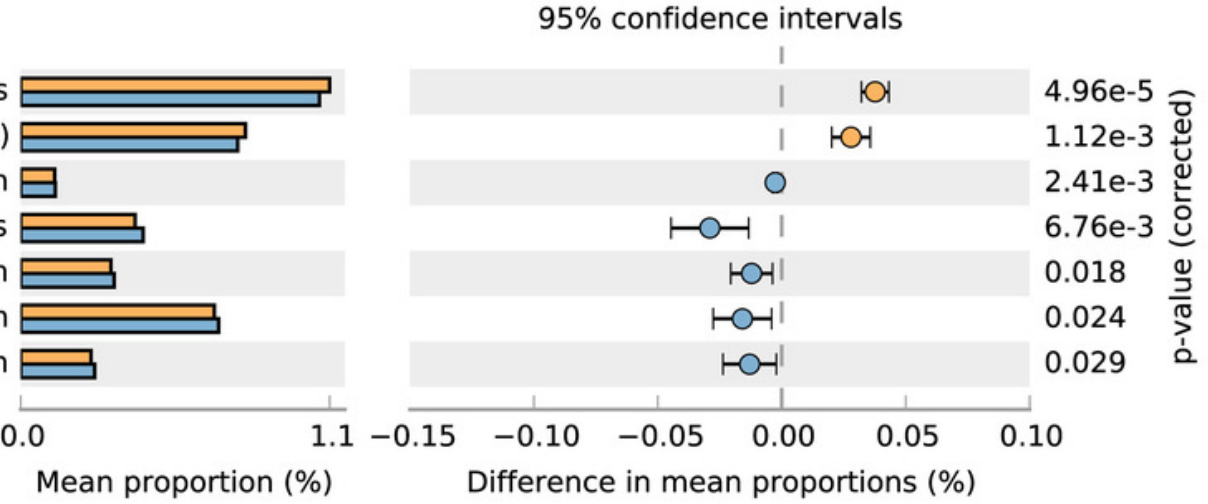


\section{Figure 6}

Relative abundance of predicted soil fungal functions

Relative abundance of predicted soil fungal functions (a) and relative abundance of fungal functional OTUs inferred by FUNGuild belong to wood saprotrophs (b) and plant pathogens (c). Full data supplied in Table S2-S4. I-Sugarcane, intercropped sugarcane. M-Soybean, soybean monoculture; I-Soybean, intercropped soybean. 

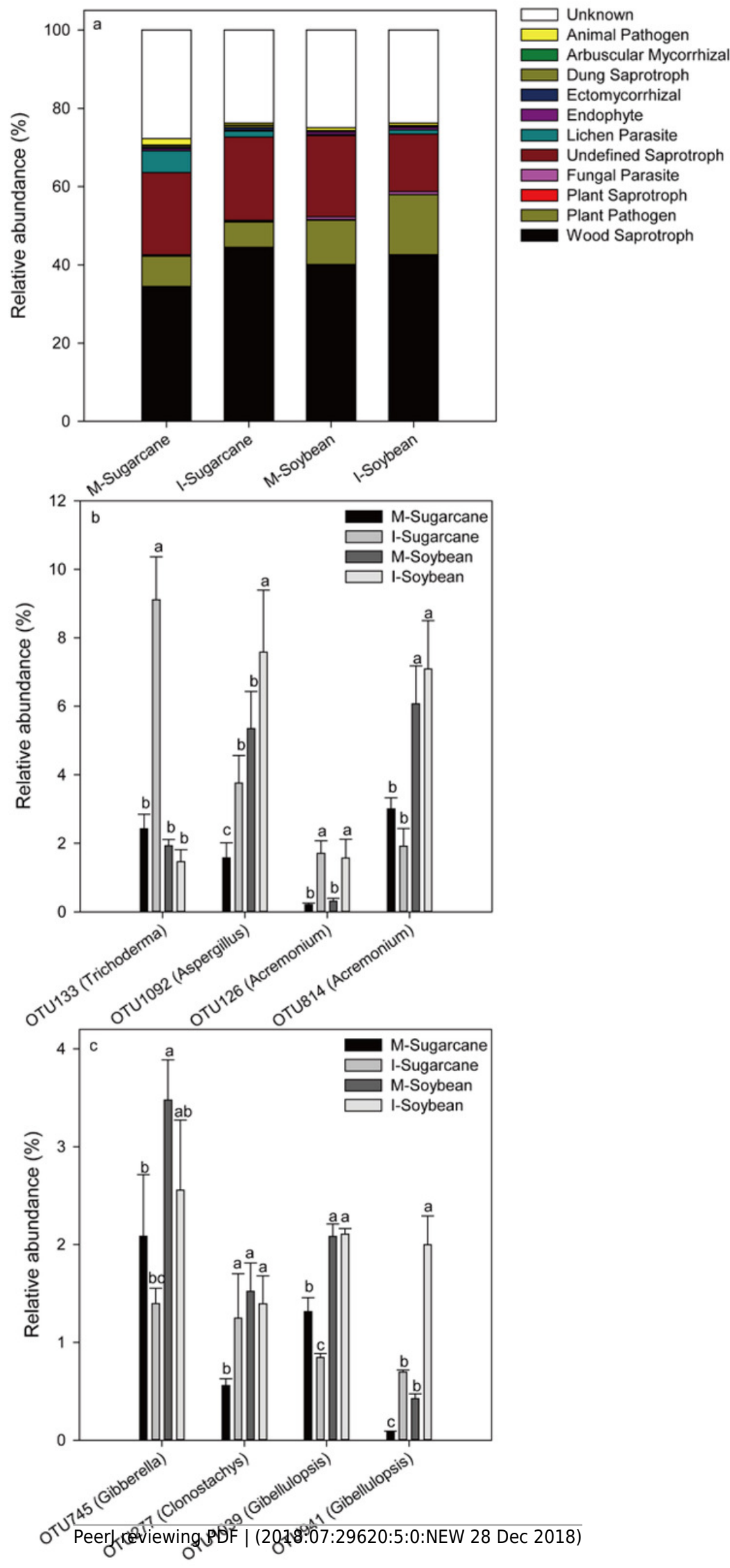


\section{Table $\mathbf{1}$ (on next page)}

Soil physiochemical properties at different culture mode

The soil physiochemical properties and microbial biomass carbon (MBC) and nitrogen (MBN) in each soil are shown in the table. Values are the means $\pm S E(n=3)$. M-Sugarcane, sugarcane monoculture; I-Sugarcane, intercropped sugarcane. M-Soybean, soybean monoculture; I-Soybean, intercropped soybean. 


\begin{tabular}{|c|c|c|c|c|c|c|c|c|c|c|}
\hline & $\mathrm{pH}$ & $\begin{array}{c}\mathrm{SOC} \\
\left(\mathrm{g} \mathrm{kg}^{-1}\right)\end{array}$ & $\begin{array}{c}\mathrm{TN} \\
\left(\mathrm{g} \mathrm{kg}^{-1}\right)\end{array}$ & $\begin{array}{l}\mathrm{NH}_{4}^{+}-\mathrm{N} \\
\left(\mathrm{mg} \mathrm{kg}^{-1}\right)\end{array}$ & $\begin{array}{l}\mathrm{NO}_{3}^{-}-\mathrm{N} \\
\left(\mathrm{mg} \mathrm{kg}^{-1}\right)\end{array}$ & $\begin{array}{c}\text { DOC } \\
\left(\mathrm{mg} \mathrm{kg}^{-1}\right)\end{array}$ & $\begin{array}{c}\mathrm{DON} \\
\left(\mathrm{mg} \mathrm{kg}^{-1}\right)\end{array}$ & $\begin{array}{c}\mathrm{MBC} \\
\left(\mathrm{mg} \mathrm{kg}^{-1}\right)\end{array}$ & $\begin{array}{c}\mathrm{MBN} \\
\left(\mathrm{mg} \mathrm{kg}^{-1}\right)\end{array}$ & $\begin{array}{c}\text { Available N } \\
\left(\mathrm{mg} \mathrm{kg}^{-1}\right)\end{array}$ \\
\hline M-Sugarcane & $6.73 \pm 0.06 \mathrm{a}$ & $16.25 \pm 0.28 \mathrm{c}$ & $0.73 \pm 0.06 b$ & $5.66 \pm 066 \mathrm{c}$ & $2.02 \pm 0.19 \mathrm{a}$ & $97.67 \pm 2.51 b$ & $0.91 \pm 0.01 \mathrm{~b}$ & $131 \pm 21.66 b$ & $6.40 \pm 0.57 \mathrm{ab}$ & $8.58 \pm 0.48 b$ \\
\hline I-Sugarcane & $6.13 \pm 0.15 b$ & $17.15 \pm 0.21 \mathrm{a}$ & $0.81 \pm 0.01 \mathrm{a}$ & $8.10 \pm 0.25 b$ & $0.42 \pm 0.10 \mathrm{~d}$ & $109 \pm 3.61 \mathrm{a}$ & $0.79 \pm 0.03 b$ & $198 \pm 13.08 \mathrm{a}$ & $8.12 \pm 0.51 \mathrm{a}$ & $9.65 \pm 0.08 b$ \\
\hline M-Soybean & $5.97 \pm 0.21 b$ & $16.30 \pm 0.57 b c$ & $0.81 \pm 0.02 \mathrm{a}$ & $6.68 \pm 0.87 b c$ & $2.00 \pm 0.29 b$ & $90.33 \pm 1.52 \mathrm{c}$ & $0.62 \pm 0.10 \mathrm{c}$ & $133 \pm 26.46 b$ & $5.60 \pm 0.06 \mathrm{c}$ & $12.30 \pm 0.58 \mathrm{a}$ \\
\hline I-Soybean & $5.45 \pm 0.06 \mathrm{c}$ & $16.93 \pm 0.08 \mathrm{ab}$ & $0.77 \pm 0.03 \mathrm{ab}$ & $10.35 \pm 1.18 \mathrm{a}$ & $1.17 \pm 0.18 \mathrm{c}$ & $106 \pm 3.61 \mathrm{ba}$ & $1.10 \pm 0.14 \mathrm{a}$ & $234 \pm 27.62 \mathrm{a}$ & $6.69 \pm 0.40 \mathrm{a}$ & $12.62 \pm 0.51 \mathrm{a}$ \\
\hline
\end{tabular}




\section{Table 2 (on next page)}

Spearman's correlations between microbial community structure and microbial activity.

$* * P<0.01$ and $* P<0.05$ indicate significant correlations 
1

\begin{tabular}{llll}
\hline & $\begin{array}{l}\text { Fungal } \\
\text { community }\end{array}$ & $\begin{array}{l}\text { Ratio of carbon- and nitrogen- } \\
\text { use efficiency }\end{array}$ & $\begin{array}{l}\text { Soil } \\
\text { respirations }\end{array}$ \\
\hline Bacterial Community & -0.034 & $0.787^{* *}$ & $0.609^{*}$ \\
Fungal Community & & -0.392 & 0.537 \\
\hline
\end{tabular}

2 